\title{
Penentuan Teknologi Anaerob Sebagai Upaya Penanganan Persampahan Berdasarkan Konsep Teknologi yang Ramah Lingkungan di Kelurahan Karang Pule Kecamatan Sekarbelah Kota Mataram
}

\author{
Ima Rahmawati Sushanti dan Agung Panji Utomo \\ Program Studi Perencanaan Wilayah \& Kota, Univ. Muhammadiyah Mataram \\ imarahmawati77@gmail.com
}

\section{INFO ARTIKEL}

\section{Riwayat Artikel:}

Diterima:20-11-2016

Disetujui:03-02-2017

\section{Kata Kunci:}

Konsep

Perencanaan

Pencemaran

Lingkungan

Teknologi

Persampahan

\section{A. LATAR BELAKANG}

Kota Mataram adalah ibu kota Nusa Tenggara Barat yang berda di pulau Lombok yang merupakan salah satu kota yang memiliki banyak potensi, salah satunya adalah potensi industri. Keberadaan industri ini sangat berperan penting dalam pembangunan dan dapat pengembangan ekonomi suatu wilayah karena mampu meningkatkan pendapatan dan memberikan lapangan perkerjaan bagi masyarakat sekitar yang ada di wilayah tersebut. Keberadaan industri sendiri dapat memberikan berbagai damppak baik positif maupun dampak negative
ABSTRAK

\begin{abstract}
Abstrak:Penelitian ini bertujuan untuk memntukan konsep teknologi yang sesuai untuk mengatasi persoalan - persoalan persampahan yang terjadi di wilayah tersebut. Metode yang digunakan dalm penelitian ini adalah deskriptif kualitatif dengan pengumpulan data primer, melalui observasi langsung dan kuesioner. Hasil penelitian menunjukan bahwa Berdasarkandari berbagai alternatif teknologi yang tersedia, teknologi yang terpilih yang akan diimplementasikan di Kelurahan Karang Pule Kecamatan Sekarbela untuk mengatasi volume sampah yang berlebihan adalah teknik 3P dan teknologi anaerobik yang menghasilkan biogas yang dapat dimanfaatkan untuk keperluan bahan bakar genset ataupun penggerak turbin pembangkit listrik tenaga uap. Selain itu gas yang dihasilkan dapat digunakan sebagai keperluan memasak dan pembuatan kompos dengan mutu yang tinggi.
\end{abstract}

\begin{abstract}
This study aims to determine the concept of technology that is suitable for dealing with waste problems that occur in the region. The method used in this study is descriptive qualitative with primary data collection, through direct observation and questionnaires. The results showed that based on various available technological alternatives, the selected technology to be implemented in Karang Pule Village, Sekarbela Subdistrict to overcome excessive volumes of waste is the 3P technique and anaerobic technology that produces biogas which can be used for generator fuel generator or generator turbine drive steam power. In addition, the gas produced can be used as a necessity for cooking and composting with high quality.
\end{abstract}

yang akan dapat berpengaruh dalam kehidupan masyarakat yang ada di kawasan tersebut.

Kelurahan Karang Pule, Kecamatan Sekarbela Kota Mataram yang merupakan salah satu kelurahan yang ditetapkan sebagai klaster industri kecil unggulan untuk kerajinan Mutiara, Emas, Perak (MEP) di Kota Mataram. Berdasarkan Peratuaran Daerah No. 12 Tahun 2011 tentang Rencana Tata Ruang Wilayah (RTRW) Kota Mataram tahun 2011 - tahun 2031, Kecamatan Sekarbela termasuk dalam pengembangan kawasan perumahan. Sedangkan Kelurahan Karang Pule ditetapkan sebagai kawasan pariwisata belanja dan pengembangan industri kecil.Selain potensi yang dimiliki, muncul berbagai permasalahan seperti maslah 
lingkungan, ekonomi dan social. Namun dampak tersebut belum dapat terselesaikan yaitu dari aspek lingkungan yang masih menjadi catatan penting di kawasan permukiman yang sekaligus menjadi wadah berlangsungnya kegiatan masyarakat termasuk kegiatan industri yang akan mengakibatkan timbulnya permukiman yang tidak layak huni. Permukiman yang tidak layak huni dapat menimbulkan ketidakseimbangan dan akan mempengaruhi aspek - aspek yang berperan penting dalam pembangunan dan pengembangan suatu wilayah.

Pengaruh yang ditimbulkan oleh masing - masing kawasan industri berbeda - beda sesuai dengan karakteristik dan potensi di wilayah karang pule serta pada sektor - sektor tertentu yang berada pula. Dengan demikian, untuk mengatasi permasalahan lingkungan yang terjadi saat ini di lokasi prioritas yang dimana dilakukannya pertimbangan criteria kawasan permukiman kumuh agar dapat menyesuaikan peruntukan lokasi tata ruang, letak, kedudukan, tingkat kepadatan penduduk, tingkat kepadatan bangunan, kondisi fisik, sosial, dan ekonomi.

Keberadaan klaster industri Mutiara, Emas, Perak (MEP) di Kelurahan Karang Pule menimbulkan pengaruh terhadap kondisi sosial,ekonomi dan lingkungan. Dampak pengaruh terhadap lingkungan, menjadi sorotan utama yang berakibat fatal terhadap kelangsungan kegiatan masyarakat yang ada di kawasan tersebut seperti terjadinya pencemaran, dan terbentuknya permukiman kumuh di sekitar kawasan industri dikarenakan kondisi kegiatan industri yang berada di dalam permukiman waraga sekitar (Sushanti, Ima R, dan Fitri, Intan S, 2016).

\section{B. METODE PENELITIAN}

Lokasi dari penelitian ini berada di Keluraha Karang Pule, Kecamatan Sekarbela Kota Mataram.Pendekatan yang digunakan dalam penelitian ini merupakan pendekatan rasionalistik yang bersumber dari teori dan kebenaran empirik.Jenis penelitian yang digunakan adalah deskriptif kualitatif dengan menggambarkan secara sistimatis mengenai suatu keadaan, situasi, program tertentu (Singarimbun, ddk. 2008).Metode pengumpulan data yang digunakan adalah denganpengumpulan data secara primer berupa observasi secara langsung dan kuesioner.

\section{HASIL DAN PEMBAHASAN}

\section{Program Prioritas Kelurahan Karang Pule}

Dalam menentukan konsep teknologi yang akan diterapkan di Kelurahan Karang Pule Kecamatan sekarbela harus berpedoman dengan berdasarkan visi dan misi, tujuan, sasaran, strategi dan kebijakan kelurahan. Disamping tetap memperhatikan kepada kerangka acuan program pembangunan Kota Mataram, dengan adanya program umum, program perioritas maupun program unggulan yang ada di kelurahan karang pule itu sendiri. Adapun program - program unggulan kelurahan karang pule yaitu:

a. Untuk peningkatan pencapaian pengrajin emas, perak dan mutiara yang diharapakan mampu meningkatkan pendapatan masyarakat yang ada di kelurahan karang pule

b. Normalisasi saluran yang dilakukan untuk menghindari terjadinya banjir dan tercapainya lingkungan yang sehat.

c. Program rumah kumuh berkelanjutan.

d. Pemerataan jaminan kesehatan nasional.

e. Program prona.

f. Bantuan air bersih.

g. Program kelistrikan.

\section{Isu Strategis}

Isu strategis pada Lingkungan Karang Pule di Kecamatan Sekarbela yang didapatkan melalui hasil kuesioner kepada masyarakat berkenaan dengan teknologi berkelanjutan menjadi harapan terhadap kesejahteraan masyarakat dapat dilihat pada table berikut:

Tabel 1

Isu strategis setiap Lingkungan di wilayah Kecamatan Sekarbela

\begin{tabular}{|c|c|c|}
\hline No & Kelurahan & Isu strategis \\
\hline 1 & Karang pule & $\begin{array}{l}\text { Adanya teknologi yang dapat } \\
\text { mengatasi terjadinya banjir. }\end{array}$ \\
\hline 2 & Pande mas timur & $\begin{array}{l}\text { Adanya teknologi yang dapat } \\
\text { menanggulangi dan } \\
\text { mengatasi rumah kumuh } \\
\text { dengan teknologi } \\
\text { berkelanjutan }\end{array}$ \\
\hline 3 & Pande mas barat & $\begin{array}{l}\text { Adanya teknologi yang dapat } \\
\text { menanggulangi dan } \\
\text { mengatasi cara mengelolah } \\
\text { sampah organic dan } \\
\text { anorganik }\end{array}$ \\
\hline 4 & Mas mutiara & $\begin{array}{l}\text { Adanya teknologi yang dapat } \\
\text { menanggulangi dan } \\
\text { mengatasi cara mengelolah } \\
\text { sampah dan menanggulangi } \\
\text { terjadinya banjir. }\end{array}$ \\
\hline 5 & BTN kekalik & $\begin{array}{l}\text { Adanya teknologi dalam } \\
\text { program rumah kumuh } \\
\text { berkelanjutan. }\end{array}$ \\
\hline 6 & Karang same & $\begin{array}{l}\text { Adanya teknologi dalm } \\
\text { pengelolaan sampah dan } \\
\text { menanggulangi masalah } \\
\text { banjir yang masih belum } \\
\text { dapat diatasi. }\end{array}$ \\
\hline 7 & Pande besi & $\begin{array}{l}\text { Adanya teknologi dalam } \\
\text { kelistrikan dan air bersih. }\end{array}$ \\
\hline
\end{tabular}

Sumber: Analisis

Harapan masyarakat Kelurahan Karang Pule yaitu ingin memajukan kawasan wilayahnya dengan "Memanfaatkan teknologi yang berwawasan dan ramah lingkungan dan dengan adanya teknologi yang dapat menanggulangi dan mengatasi permasalahan dengan cara mengolah dan memanfaatkannya.

Adapun masalah yang ada di Kelurahan Karang Pule adalah sebagai berikut: 
1. Kurangnya kesadaran masyarakat tentang mengatasi masalah sampah yang menjadi masalah prioritas di Kelurahan Karang Pule sehingga masih banyak sampah yang berserakan.

2. Kurangnya pengetahuan masyarakat dalam memilah dan mengelola jenis sampah organik dan anorganik.

\section{Perencanaan Taktis}

\section{a. AlternativeTeknologi Berkelanjutan}

Teknologi anaerobik adalah teknologi alternative yang dipilih sebagai proses dekomposisi (penguraian) biomassa (residu/sampah) secara mikrobilogis dalam kondisi anaerobic (tanpa oksigen). Secara garis besar bahan baku yang di perlukan untuk teknologi anaerobik adalah berupa sampah pasar tradisional (berjenis sampah basah), mikroorganisme, dan air. Sedangkan perangkat yang diperlukan dalam teknologi anaerobik terdiri dari digester sebagai tempat berlangsungnya proses anaerobik, penampung biogas, dan perangkat pemanfaatan biogas yang dihasilkan, serta serta beberapa komponen pendukung seperti stop kran, pipa, dan perangkat pengaman. Hal ini dengan jelas mencerminkan bahwa teknologi anaerobik adalah teknologi yang murah dan ramah lingkungan, karena semua bahan baku tersebut dapat diperoleh dengan cara mudah dan dalam jumlah yang besar. Sedangkan untuk digester dan penampung gas dapat dibuat dari bahan- bahan bangunan seperti semen dan pasir, sehingga biaya pembuatanya relative murah.

Tabel 2.

Nilai investasi teknologi anaerob digester

\begin{tabular}{|c|c|c|}
\hline No & Komponen Biaya & Jumlah Biaya (Rp) \\
\hline 1 & Tangki biogas & 1.000 .000 \\
\hline 2 & Micro turbin & 749.000 \\
\hline 3 & Biogas cleaning sistem & 245.000 \\
\hline 4 & Heat recovey sistem & 1.200 .000 \\
\hline 5 & Emission control sistem & 1.000 .000 \\
\hline
\end{tabular}

\section{b. Teknologi Alternatif Dalam Pengolahan Sampah}

Tranformasi fisik, meliputi pemisan komponen sampah (shorting) dan pemadatan (compacting), yang tujuannya adalah mempermudah penyimpanan dan pengangkutan.

Pembakaran (incinerate), merupakan teknik pengolahan sampah yang dapat mengubah sampah menjadi bentuk gas, sehingga volumenya dapat berkurang hingga 90-95\%.Meski merupakan teknik yang efektif, tetapi bukan merupakan teknik yang dianjurkan.Hal ini disebabkan karena teknik teknik tersebut sangat berpotensi untuk menimbulkan pencemaran udara.
Pembuatan kompos (composting), Kompos adalah pupuk alami (organik) yang terbuat dari bahan - bahan hijauan dan bahan organik lain yang sengaja ditambahkan untuk mempercepat proses pembusukan, misalnya kotoran ternak atau bila di pandang perlu, bias ditambahkan pupuk buatan pabrik, seperti urea (Wied, 2004). Berada dengan proses pengolahan sampah yang lainya, maka pada proses pembuatan kompos baik bahan baku, tempat pembuatan maupun cara pebuatan dapt dilakukan oleh siapapun dan dimanapun.

Energy recovery, yaitu transformasi sampah menjadi energy, baik energi panas maupun energi listrik. Metode ini telah banyakdikembangkan di Negara - Negara maju yaitu pada instalasi yang cukup besar dengan kapasitas \pm 300 ton/hari dapat dilengkapi dengan pembangkit listrik sehingga energi listrik ( $\pm 96.000 \mathrm{MWH} /$ tahun $)$ yang dihasilkan dapat dimanfaatkan untuk menekan biaya proses pengelolaan.

\section{c. Dampak alternative penanganan samapah}

Dalam mengolah sampah, tentunya memiliki dampak, baik berupa dampak positif maupun dampak negatif, seperti yang ditunjunjukan pada Tabel 3. Hal ini dapat menjadi pertimbangan dalam menentukan penanganan yang tepat persampahan di kelurahan Karang Pule

Tabel 3

Dampak Positif dan Negatif dari Teknologi Sampah

\begin{tabular}{|c|c|c|c|}
\hline \multirow[b]{2}{*}{ No } & \multirow{2}{*}{$\begin{array}{c}\text { Alternatif } \\
\text { Teknologi } \\
\text { Sampah }\end{array}$} & \multicolumn{2}{|c|}{ Dampak } \\
\hline & & positif & Negatif \\
\hline 1 & $\begin{array}{l}\text { Transformasi } \\
\text { fisik }\end{array}$ & $\begin{array}{ll}\text { - } & \text { Mempermudah } \\
\text { penyimpanan } \\
\text { dan } \\
\text { pengangkutan } \\
\text { - Dapat } \\
\text { mngetahui } \\
\text { sampah organic } \\
\text { dan anorganik }\end{array}$ & $\begin{array}{ll}\text { Banyaknya } \\
\text { masyarakat } \\
\text { yang malas } \\
\text { dalam } \\
\text { memilah } \\
\text { sampah dan } \\
\text { menyimpann } \\
\text { ya. } \\
\text { Memakan } \\
\text { waktu yang } \\
\text { lumayan lama }\end{array}$ \\
\hline 2 & pembakaran & $\begin{array}{l}\text { - Dapat } \\
\text { mengurangi } \\
\text { jumlah sampah } \\
\text { yang banyak }\end{array}$ & $\begin{array}{l}\text { - Dapat } \\
\text { mengganggu } \\
\text { aktivitas } \\
\text { masyarakat } \\
\text { karena dapat } \\
\text { pencemaran } \\
\text { udara } \\
\text { - Dampaknya } \\
\text { sangat } \\
\text { berbahaya } \\
\text { dapat } \\
\text { menimbulkan } \\
\text { masalah, baik } \\
\text { dari } \\
\text { lingkungan } \\
\text { sampai } \\
\text { dengan } \\
\text { kesehatan. }\end{array}$ \\
\hline 3 & $\begin{array}{l}\text { Pembuatan } \\
\text { kompos }\end{array}$ & $\begin{array}{l}\text { - Dapat } \\
\text { menggunakan } \\
\text { sebagai pupuk }\end{array}$ & $\begin{array}{l}\text { Belum } \\
\text { mengetahui } \\
\text { cara dalam }\end{array}$ \\
\hline
\end{tabular}




\begin{tabular}{lll}
\hline alami pada & mengolah \\
sampah yang & sampah atau \\
& organik atau & teknik \\
& biasa disebut & pembuatan \\
& dengan pupuk & kompos \\
& urea & (composting) \\
- & Dapat menjadi & itu sendiri \\
& usaha masyarak & \\
& dalam bidang & \\
perkebunan dan & \\
& lainnya & \\
\hline
\end{tabular}

\section{d. Teknologi Berkelanjutan Terpilih}

Berdasarkandari berbagai alternatif teknologi yang tersdia, teknologi yang terpilih yang akan diimplementasikan di Kelurahan Karang Pule Kecamatan Sekarbela untuk mengatasi volume sampah yang berlebihan adalah teknik $3 \mathrm{P}$ dan teknologi anaerobik yang menghasilkan biogas yang dapat dimanfaatkan untuk keperluan bahan bakar genset ataupun penggerak turbin pembangkit listrik tenaga uap. Selain itu gas yang dihasilkan dapat digunakan sebagai keperluan memasak dan pembuatan kompos dengan mutu yang tinggi. Pemilihan teknologi ini diharapakan akan menjawab masalah dari kondisi yang ada di Kelurahan Karang Pule karena teknologi yang terpilih banyak memberikan manfaat bagi masyarakat untuk keperluan sehari - hari dan dapat mengurangi volume sampah, Teknologi pilihan:

1. Bahwa konsep teknologi persampahan yang sesuai adalhkawasan berbasis kawasan ramah lingkungan dengan teknologi terpilih adalah Teknologi anaerobik.

2. Kawasan ramah lingkungan.

Pada pelaksanaannya industri ramah lingkungan diharapakan dalam proses industri melakukan strategi mencegas, mengurangi, dan menghilangkan terbentuknya limbah sebagai bahan pencemar lingkungan. Hal tersebut dapat berjalan bila dalam aktivitasnya telah dirancangmulai dari bahan baku, teknologi proses sampai akhir kegiatan adalah yang ramah lingkungan. Untuk mendukung terlaksananya strategi tersebut diperlukan suatu perubahan yang mendasar dalam hal komitmen serta perilaku pimpinan dan karyawan, penyediaan sarana dan prasarana penunjang dan peningkatan kompetensi SDM. Industri yang menerapkan strategi ramah lingkungan mempunyai tujuan:

1. Refine, adalah penggunaan bahan atau proses yang lebih ramah lingkungan dibandingkan dengan bahan atau pross yang ada saat ini

2. Reduce, adalah pengurangan jumlah limbah atau kehilangan dengan optimalisasi proses atau operasionalmenghasilkan limbah yang mengalami pemborosa. Contoh: mengganti keran atau pipa bocor, memasang alat penangkap ceceran/lelehan.
3. Reuse, adalah pemakaian kembali bahan bahan atau limbah pada proses yang berbeda.

4. Recycle, adalah penggunaan kembali bahan bahan atau sumber daya untuk proses yang sama.

5. Recovery, adalah kegiatan pengambilan kembali sebagian material penting dari aliran limbah untuk pemanfaatan ulang dalam proses proses pemanfaatan untuk proses atau keperluan yang lainnya.

6. Retrieve Energy, adalah pemanfaatan limbah untuk digunakan sebagai bahan bakar atau dalam arti yang luas adalah penghematan energy dalam proses produksi.

Secara imiah, biogas yang dihasilkan dari reaktor sampah pasar tradisonal ini adalah gas yang bersifat mudah terbakar (Flammable). Gas ini dihasilkan dari proses fermentasi bahan bahan organik oleh bakteri anaerob (bakteri yang hidup dalam kondisi tanpa udara) seperti Pseudomonas, flavobacterium, dan methanobacterium. Bila sampah - sampah basah tersebut membusuk, akan dihasilkan gas metana $\left(\mathrm{CH}_{4}\right)$. Gas metana terkenal luas sebagai bahan bakar ramah lingkungan, karena dapat terbakar dengan sempurna sehingga tidak menghasilkan asap yang berpengaruh buruk terhadap kualitas udara. Karena sifatnya tersebut, gas metana merupakan gas metana merupakan gas bernilai ekonomis tinggi. Dari 5 ton bahan baku sampah pasar tradisional yang diolah melalui teknologi anaerobik akan menghasilkan o,9 sampai dengan 1,8 meter kubik biogas per hari. Dengan jumlah biogas yang sedemikian maka akan cukup digunakan untuk memasak bagi 20 warung disekitar pasar. Apabila jumlah bahan baku yang digunakan lebih banyak lagi, maka biogas tersebut dapat dimanfaatkan untuk keperluannya bahan bakar genset ataupun penggerak turbin pembangkit listrik tenaga uap. Selain gas metana, produk bermutu lainya dari teknologi anaerobik adalah pupuk organik yang siap pakai dengan kandungan unsur hara yang jauh lebih tinggi dibanding bahan baku awalnya. Hal ini dikarenakan telah terjadi pemekatan berbagai unsur hara dalam residu proses anaerobik karena lapasnya senyawa kimia karbon dan hidrogen dalam proses pembentukan gas metana. Disamping dua produk diatas teknologi anaerobik juga mempunyai nili tambah yaitu:

1. Biogas diharapkan dapat mengurangi ketergantungan masyarakat terhadap penggunaan minyak yang jumlahnya terbatas dan harganya yang cukup mahal. 
2. Teknologi ini dapat mengurangi pencemaran lingkungan dan menciptakan kondisi pasar tradisional yang bersih, sehat, dan nyaman.

3. Mengatasi kelangkaan pupuk.

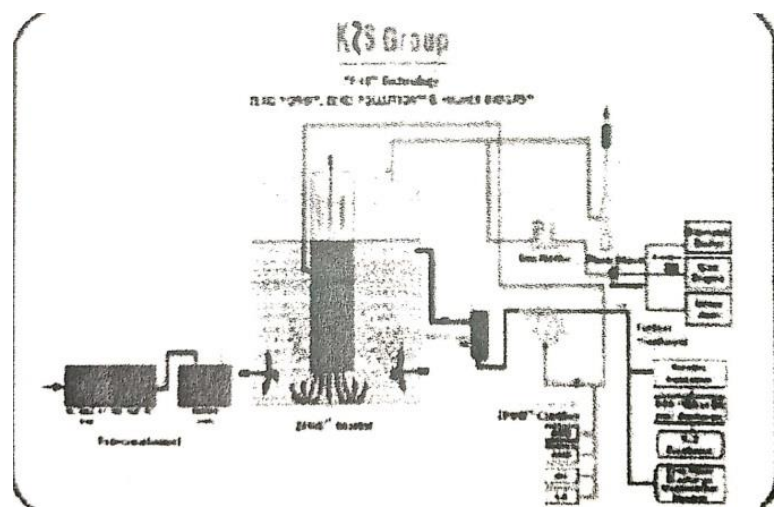

Ganbar 1. Siklus Teknologi Anaerob

\section{KeSimpulan}

Berdasarkandari berbagai alternatif teknologi yang tersdia, teknologi yang terpilih yang akan diimplementasikan di Kelurahan Karang Pule Kecamatan Sekarbela untuk mengatasi volume sampah yang berlebihan adalah teknik ${ }_{3} \mathrm{P}$ dan teknologi anaerobik yang menghasilkan biogas yang dapat dimanfaatkan untuk keperluan bahan bakar genset ataupun penggerak turbin pembangkit listrik tenaga uap. Selain itu gas yang dihasilkan dapat digunakan sebagai keperluan memasak dan pembuatan kompos dengan mutu yang tinggi. Pemilihan teknologi ini diharapakan akan menjawab masalah dari kondisi yang ada di Kelurahan Karang Pule

\section{DAFTAR RUJUKAN}

[1] Cantanese, A. \& Synder, J. 1979. Introduction To Urban Planing.Diterjemahkan oleh susongko, Ir. Pengantar Perencanan Kota. Jakarta: Erlangga

[2] Melville C. Branch, 1996. Perencanaan Kota Komprehensip: Pengantar dan Penjelasan. Diterjemahkan oleh: Bambang Hari wibisono. Yogyakarta: Gadjah University Prees

[3] Peter Hall, 1992. Urban and Regional Planing. London: Routlege

[4] Sondang P. Siagian, 1994. Fungsi-Fungsi Managemen). Jakarta: Bumi Akasara

[5] Brundtlant Report, 1987, Our Common Future. Oxford : Oxford University Press

[6] Franco archibugi, 2008. Planning Theory : From the Political Debate to the Methodological Reconstruction. Springer.

[7] Lingkert Rensis, 1932. A Techique For the Measurement of Attitude. Jurnal Psikologi 140 (55): Hal.1-55
[8] Peraturan Daerah Pemerintah Provinsi Nusa Tenggara Barat Pasal 11 ayat 2 tentang rencana tata ruang wilayah profinsi NTB tahun 2009-2029

[9] Peraturan Daerah Mataram No.12 Tahun 2011 tentang rencana tata ruang wilayah kota mataram tahun 2011-2031. Pasal 22

[10]UUD 1945 Pasal $28 \mathrm{H}$ ayat (1) dan UUD RI NO 18 tentang pengolaan sampah

[11] www.mataramkota.bps.go.id

[12] www.radarplanologi.com/2015/10/pengantarumum-perencanaan-html

[13]http//dosenit.com/kuliah-it/teknologiinformasi/penegrtian-teknologi-menurut-para-ahli- 